Review Article

\title{
The Ambiguous Relationship of Oxidative Stress, Tau Hyperphosphorylation, and Autophagy Dysfunction in Alzheimer's Disease
}

\author{
Zhenzhen Liu, ${ }^{1,2}$ Tao Li, ${ }^{2}$ Ping Li, ${ }^{2}$ Nannan Wei, ${ }^{2}$ Zhiquan Zhao, ${ }^{2}$ Huimin Liang, \\ Xinying Ji, ${ }^{2}$ Wenwu Chen, ${ }^{3,4}$ Mengzhou Xue, ${ }^{3,4}$ and Jianshe Wei ${ }^{1,2}$ \\ ${ }^{1}$ Institute of Neuroscience, Henan Polytechnic University, Jiaozuo 454000, China \\ ${ }^{2}$ Laboratory of Brain Function and Molecular Neurodegeneration, Institute for Brain Science Research, School of Life Sciences, \\ Henan University, Kaifeng 475004, China \\ ${ }^{3}$ Department of Neurology, The First Affiliated Hospital, Henan University, Kaifeng 475000, China \\ ${ }^{4}$ Institute of Neurological Disorder, Henan University, Kaifeng 475000, China
}

Correspondence should be addressed to Mengzhou Xue; menzhouxue@gmail.com and Jianshe Wei; jswei@henu.edu.cn

Received 7 October 2014; Revised 2 March 2015; Accepted 3 March 2015

Academic Editor: Eugene A. Kiyatkin

Copyright (C) 2015 Zhenzhen Liu et al. This is an open access article distributed under the Creative Commons Attribution License, which permits unrestricted use, distribution, and reproduction in any medium, provided the original work is properly cited.

\begin{abstract}
Alzheimer's disease $(\mathrm{AD})$ is the most common form of dementia. The pathological hallmarks of $\mathrm{AD}$ are amyloid plaques [aggregates of amyloid-beta $(\mathrm{A} \beta)$ ] and neurofibrillary tangles (aggregates of tau). Growing evidence suggests that tau accumulation is pathologically more relevant to the development of neurodegeneration and cognitive decline in $\mathrm{AD}$ patients than $\mathrm{A} \beta$ plaques. Oxidative stress is a prominent early event in the pathogenesis of $\mathrm{AD}$ and is therefore believed to contribute to tau hyperphosphorylation. Several studies have shown that the autophagic pathway in neurons is important under physiological and pathological conditions. Therefore, this pathway plays a crucial role for the degradation of endogenous soluble tau. However, the relationship between oxidative stress, tau protein hyperphosphorylation, autophagy dysregulation, and neuronal cell death in $\mathrm{AD}$ remains unclear. Here, we review the latest progress in $\mathrm{AD}$, with a special emphasis on oxidative stress, tau hyperphosphorylation, and autophagy. We also discuss the relationship of these three factors in AD.
\end{abstract}

\section{Introduction}

Alzheimer's disease (AD) is the most common form of dementia in the elderly and a chronic neurodegenerative disease characterized by widespread degeneration of neurons. An estimated 37 million people worldwide currently have $\mathrm{AD}$, which is estimated to increase to 65.7 million by 2030 and 115.4 million by $2050[1,2]$. AD is a growing health concern in society because patients suffer from progressive functional impairments, emotional distress, loss of independence, and behavioral deficits. It is characterized by the presence of two types of neuropathological hallmarks: senile plaques (SPs) and intracellular neurofibrillary tangles (NFTs). SPs predominantly consist of extracellular amyloid $\beta$-peptide (A $\beta$ ) deposits. NFTs are formed by intraneuronal aggregation of hyperphosphorylated tau. The amyloid cascade hypothesis theory proposes a dysregulation of amyloid precursor protein processing. This event leads to AD pathogenesis, which involves the aggregation of $A \beta$ (particularly $A \beta 42$ ), neuritic plaque formation, and consequently the formation of NFTs followed by the disruption of synaptic connections, neuronal death, and cognitive deficits (dementia) [3]. Increasing evidence suggests that $A \beta$ oligomers ( $A \beta O s$ ) may be the primary cause of $\mathrm{AD}$ because they have a greater correlation with dementia than insoluble $\mathrm{A} \beta 42$ [4]. These $\mathrm{A} \beta \mathrm{O}$ s bind to a putative receptor and activate the receptor tyrosine kinase EphA4 and Fyn. A $\beta$ Os binding triggers aberrant activation of NMDARs and abnormal increase in postsynaptic $\mathrm{Ca}^{2+}$. The following events include increased generation of reactive oxygen species (ROS), and membrane lipid peroxidation; mitochondrial fragmentation, $\mathrm{Ca}^{2+}$ induced $\mathrm{Ca}^{2+}$ release 
(CICR), then produces altered surface expression and dysregulation of receptor function, excitotoxicity, dendritic spine retraction, and elimination [4-6].

$\mathrm{A} \beta$ also plays a crucial role in inducing neuronal oxidative stress $[7,8]$. A $\beta$-mediated mitochondrial oxidative stress causes hyperphosphorylation of tau in AD brains [8-10]. Mounting evidence clearly links tau to neurodegeneration, indicating that tau hyperphosphorylation may be the necessary point in neural dysfunction and death. However, whether autophagic dysfunction is involved in neuronal death during this event still remains unknown. Recent studies have indicated the importance of defective autophagy in the pathogenesis of aging and neurodegenerative diseases [11-14], especially in AD [15-17]. Autophagy may increase the formation of autophagosome in $\mathrm{AD}$, and autophagic dysfunction may induce the pathogenesis of $\mathrm{AD}$, particularly at the late stage of $\mathrm{AD}$ [18-22]. However, the relationship between oxidative stress, tau protein hyperphosphorylation, autophagic dysfunction, and neuronal cells death in $\mathrm{AD}$ remains elusive. In this review, we summarize the latest progress in research focused on oxidative stress, tau hyperphosphorylation, and autophagic dysfunction and their relationship with $\mathrm{AD}$.

\section{Oxidative Stress in AD}

In experimental models and human brain studies of $\mathrm{AD}$, oxidative stress has been shown to play an important role in neurodegeneration $[10,23,24]$. Generally, oxidative stress is caused by the imbalance between reactive oxygen species (ROS) $\left(\mathrm{O}_{2}{ }^{-}, \mathrm{H}_{2} \mathrm{O}_{2}, \mathrm{HO}_{2}\right.$, and $\left.\cdot \mathrm{OH}\right)$ and the breakdown of chemically reactive species, by reducing agents and antioxidant enzymes, such as manganese superoxide dismutase $\left(\mathrm{SOD}_{2}\right)[25,26]$. This disequilibrium may result from disease, stressors, or environmental factors. High ROS levels lead to the accumulation of oxidized proteins, lipids, and nucleic acids, thereby directly impairing cellular function if not removed or neutralized [27]. Oxidative damage to cellular components is likely to result in the alteration of membrane properties, such as fluidity, ion transport, enzyme activities, protein cross-linking, and eventually cell death.

Oxidative stress has been reported to be one of the earliest events in AD. Several risk factors for AD may cause or promote oxidative damage, such as advanced age $[28,29]$ and apolipoprotein E (APOE) $\varepsilon 4$ alleles [30, 31]. Medical risk factors include traumatic brain injury [32], stroke [33], hypertension [34], diabetes mellitus [35], hypercholesterolemia [36], and hyperhomocysteinemia [37]. Environmental and lifestyle-related risk factors include aluminum exposure [38], smoking [39], high calorie intake [40], vitamin D deficiency [41], lack of exercise [42], and lack of intellectual activities [43-45]. Mitochondrial dysfunction is known to be associated with oxidative stress and thus may be an initial trigger for enhanced $A \beta$ production during the aging process [46-48]. Both soluble and fibrillar $A \beta$ may further accelerate oxidative stress, as well as mitochondrial dysfunction $[49,50]$. The transgenic (Tg) Thyl-APP751 (SL) mouse model of AD shows increased proteolytic cleavage of APP, increased production of $\mathrm{A} \beta$, and impaired $\mathrm{Cu} / \mathrm{Zn}$-SOD activity [51]. Furthermore, oxidative stress is considered as a primary factor of NFT formation in $\mathrm{AD}[10,24,52,53]$. However, the relationship between oxidative stress and tau hyperphosphorylation remains unclear. Okadaic acid is used as a research model to induce tau phosphorylation and neuronal death in $\mathrm{AD}$. Oxidative stress combined with okadaic acid results in tau hyperphosphorylation [54]. Mitochondrial $\mathrm{SOD}_{2}$ deficiency increases the levels of Ser396 phosphorylated tau in the $\mathrm{Tg} 2576$ mouse model of $\mathrm{AD}$ [55].

\section{Tau Protein in AD}

3.1. Tau Protein Physiology and Pathology. Tau protein (known as neuronal microtubule associated protein tau) plays a large role in the outgrowth of neuronal processes and the development of neuronal polarity [56-58]. Tau protein in the central nervous system is predominantly expressed in neurons $[59,60]$, with its main function to promote microtubule assembly, stabilize microtubules, affect the dynamics of microtubules in neurons [61, 62], and inhibit apoptosis [63], particularly in axons $[64,65]$. However, recent reports suggest that excess intracellular tau is released into the extracellular culture medium via membrane vesicles [66]. In the adult human brain, tau consists of six isoforms, and the tau gene contains 16 exons. These isoforms are generated by alternative splicing of exons 2,3 , and 10 of its pre-mRNA $[67,68]$. The six tau isoforms differ from each other by the presence or absence of one or two inserts (coded by exon 2 or exons 2 and 3 ) in the $\mathrm{N}$-terminal part and the presence or absence of the second microtubule-binding repeat (encoded by exon 10) in the Cterminal portion. Depending on the alternative splicing of exon 10 , tau isoforms are termed $4 \mathrm{R}$ (four microtubulebinding domains, with exon 10) or 3R (three microtubulebinding domains, without exon 10). Adult human brain expresses both 3R-tau and $4 \mathrm{R}$-tau, whereas fetal human brain expresses only 3R-tau $[69,70]$. Immunocytochemistry and biochemical analysis indicate that the ratio of $3 \mathrm{R}$ - to $4 \mathrm{R}$-tau altered in $\mathrm{AD}$ and other neurodegenerative brain disorders [71-73], although in the normal adult human brain the level of 3R-tau is approximately equal to that of 4R-tau [74].

Tau protein normally stabilizes axonal microtubules in the cytoskeleton and plays a vital role in regulating the morphology of neurons. It has more than 30 phosphorylation sites. When tau is abnormally hyperphosphorylated, it destabilizes microtubules by decreasing the binding affinity of tau, affecting its axonal transport and resulting in its aggregation in NFTs [64]. NFTs are composed of paired helical filaments (PHF) of abnormally hyperphosphorylated tau. The pathogenesis of tau-mediated neurodegeneration is unclear but hyperphosphorylation, oligomerization, fibrillization, and propagation of tau pathology have been proposed as the likely pathological processes that induce the loss of function or gain of tau toxicity, which caused neurodegeneration [75]. Tau phosphorylation has been investigated at $\mathrm{AD}$-related sites by using recombinant human tau phosphorylated by DNA damage-activated checkpoint kinase 1 (Chk1) and checkpoint kinase 2 (Chk2) in vitro [76]. This study identified a total of $27 \mathrm{Ser} / \mathrm{Thr}$ residues as Chk1 or Chk2 target sites. Among these sites, 13 have been identified 
to be phosphorylated in $\mathrm{AD}$ brains [77]. The generation of a $\mathrm{Tg}$ mouse line overexpressing human tau441 via V337M and R406W tau mutations has been shown to accelerate the phosphorylation of human tau, inducing tau pathology and cognitive deficits [78]. Pseudophosphorylation of tau reduces microtubule interactions, disrupts the microtubule network, and exerts neurotoxicity [79]. Interestingly, doubly pseudophosphorylated tau proteins enhance microtubule assembly activity and are more potent at regulating dynamic instability [80]. However, four singly pseudophosphorylated tau proteins exhibit a loss of function at the same sites (Thr [231], Ser [262], Ser [396], and Ser [404]) [80].

3.2. Tau Protein Kinases and Phosphatase. Tau phosphorylation is mainly determined by a balance between the activation of various tau protein kinases and phosphatases and its disruption results in the abnormal phosphorylation of tau, which is observed in AD. Each tau site is phosphorylated by one or more protein kinases. Tau kinases are grouped into three classes: (1) proline-directed protein kinases (PDPK) containing glycogen synthase kinase-3 (GSK3), dual specificity tyrosine-phosphorylation-regulated kinase $1 \mathrm{~A} / \mathrm{B}$ (Dyrk1A/B), cyclin-dependent protein kinase-5 (CDK5), and mitogen activated protein kinases (MAPK) (e.g., p38, Erk1/2, and JNK1/2/3); (2) non-PDPK, including tau-tubulin kinase $1 / 2$ (e.g., casein kinase $1 \alpha / 1 \delta / 1 \varepsilon / 2$ ), microtubule affinity regulating kinases, phosphorylase kinase, cAMP-dependent protein kinase $\mathrm{A}$ (PKA), $\mathrm{PKB} / \mathrm{AKT}$, protein kinase $\mathrm{C}$, protein kinase $\mathrm{N}$, and $\mathrm{Ca}^{2+} /$ calmodulin-dependent protein kinase II (CaM kinase II); and (3) tyrosine protein kinases, including Src family kinase (SFK) members (e.g., Src, Lck, Syk, and Fyn) and Abelson family kinase members, ABL1 and ABL2 (ARG).

GSK3 (particularly GSK3 $\beta$ ) plays a key role in the pathogenesis of $\mathrm{AD}$, contributing to $\mathrm{A} \beta$ production and $\mathrm{A} \beta$ mediated neuronal death by phosphorylating tau in most serine and threonine residues and inducing hyperphosphorylation in paired helical filaments [81]. Inhibition of GSK3 prevents $\mathrm{A} \beta$ aggregation and tau hyperphosphorylation [ 82 , 83]. The involvement of CDK5 in tau phosphorylation is shown by the increase in its enzymatic activity and the absence of MT-2 cells neurite retraction in the presence of roscovitine or CDK5 siRNA [84]. Therefore, CDK5 may be a key candidate target for therapeutic gene silencing [85]. p38 MAPK has been identified as one of the kinases involved in the regulation of tau phosphorylation. Thus, under pathological conditions this kinase is likely to play a role in the hyperphosphorylation of tau [86]. CDKs and casein kinase 1 (CK1) are involved in the aggregation of $\mathrm{A} \beta$ peptides (forming extracellular plaques) and hyperphosphorylation of tau (forming intracellular NFTs). The expression pattern of CKI $\delta$ (an isoform of CK1) plays an important role in tau aggregation in AD [87]. Ser214, Ser262, and Ser409 are major phosphorylation sites of tau that are affected by PKA [88]. In P19 cells stably expressing human tau441, CaM kinase II has been shown to be involved in retinoic acid- (RA-) induced tau phosphorylation-mediated apoptosis [89].

Phosphatases are also usually classified into three classes according to their amino acids sequences, the structure of their catalytic site, and their sensitivity to inhibitors. These groups include (1) phosphoprotein phosphatase (PPP), (2) metal-dependent protein phosphatase, and (3) protein tyrosine phosphatase (PTP). Tau phosphatases belong to the PPP group (protein phosphatase [PP] 1, PP2A, PP2B, and PP5) and PTP group tumor suppressor phosphatase and tensin homolog (PTEN). The activity of PP2A, PP1, PP5, and PP2B accounts for approximately $71 \%, 11 \%, 10 \%$, and $7 \%$, respectively, in the normal human brain. However, in the AD brain, the total phosphatase activity (and including overall activity) for tau of PP2A, PP1, and PP5 is significantly decreased by $50 \%, 20 \%$, and $20 \%$, respectively [ 90$]$. PP2A contributes to abnormally hyperphosphorylated tau protein and is the most efficient phosphatase. Moreover, the inhibition of PP2A significantly plays a role in tau hyperphosphorylation [9193]. It indicated PP2A is downregulated in the Down syndrome (DS) brain and thus may be involved in the abnormal hyperphosphorylation and accumulation of tau [94].

PP2A is regulated by endogenous inhibitor- 1 of PP2A (I1PP2A) and inhibitor-2 of PP2A (I2PP2A) in mammalian tissues [95]. In $\mathrm{AD}$ brain, I2PP2A is translocated from neuronal nucleus to cytoplasm where it inhibits PP2A activity and promotes abnormal phosphorylation of tau. With inactivation of the nuclear localization signal (NLS) of $\mathrm{I} 2 \mathrm{PP} 2 \mathrm{~A},{ }^{179} \mathrm{KRK}^{181} \rightarrow{ }^{179} \mathrm{AAA}^{181}$ along with ${ }^{168} \mathrm{KR}^{169} \rightarrow$ ${ }^{168} \mathrm{AA}^{169}$ mutations in I2PP2A (mNLS-I2PP2A), I2PP2A was translocated from nucleus to the cytoplasm. Cytoplasmic retention of I2PP2A physically interacted with PP2A and inhibited its activity and induced Alzheimer-like abnormal tau protein hyperphosphorylation by the direct interaction of I2PP2A with PP2A and GSK-3 $\beta$ [96]. I2PP2A directly inhibits the activity of PP2A without affecting its expression [97]. GSK-3 activation significantly contributes to tau hyperphosphorylation by inhibiting PP2A via the upregulation of I2PP2A [98]. Okadaic acid is also considered to be a selective and potent inhibitor of serine/threonine phosphatase- 1 and PP2A, which induces hyperphosphorylation of tau under in vitro and in vivo conditions [99]. These data indicate that upregulation or downregulation of the phosphorylation system or dephosphorylation system, respectively, of tau protein may be implicated in tau pathologies.

\subsection{Tau Protein and Oxidative Stress}

3.3.1. Tau Protein Hyperphosphorylation and Oxidative Stress. Oxidative stress is believed to be a prominent early event in the pathogenesis of $\mathrm{AD}$, contributing to tau phosphorylation and the formation of neurofibrillary tangles [48]. However, the relationship and underlying mechanisms between oxidative stress and tau hyperphosphorylation remain elusive. Fatty acid oxidative products provide a direct link between the mechanisms of how oxidative stress induces the formation of NFTs in AD [100]. Data from experiments show that chronic oxidative stress increases the levels of tau phosphorylation at paired helical filaments (PHF-1) epitope (serine 396/404) via the inhibition of glutathione synthesis with buthionine sulfoximine (BSO) in an vitro model of chronic oxidative stress [9]. In primary rat cortical neuronal cultures 
stimulated by the combination of the copper chelator, cuprizone, and oxidative stress $\left(\mathrm{Fe}^{2+} / \mathrm{H}_{2} \mathrm{O}_{2}\right)$, tau phosphorylation is significantly increased by the elevated activity of GSK-3 [101]. Furthermore, treatment of rat hippocampal cells and SHSY5Y human neuroblastoma cells with $\mathrm{H}_{2} \mathrm{O}_{2}$ at the early stages of oxidative stress exposure results in tau dephosphorylation at the taul epitope by CDK5 via PP1 activation [102]. Several studies have suggested that oxidative stress is a causal factor in tau-induced neurodegeneration in Drosophila [103105]. In contrast, a fragment of tau protein has been shown to induce copper reduction, thus contributing to oxidative stress and initiating copper-mediated generation of $\mathrm{H}_{2} \mathrm{O}_{2}$ [106].

3.3.2. GSK3 $\beta, P P 2 A$, and Oxidative Stress. Oxidative stress is likely to play a critical role in tau hyperphosphorylation, which is regulated by tau protein kinase activation and the suppression of phosphatase. Tau hyperphosphorylation may be induced by oxidative stress through the direct interaction with tau protein kinase and phosphatase, particularly GSK$3 \beta$ and PP2A, respectively, because they are predominant and play an important role. A recent study has indicated that GSK-3 $\beta$ activity is upregulated under oxidative stress [107]. In human embryonic kidney 293/tau cells, $\mathrm{H}_{2} \mathrm{O}_{2}$ increases GSK-3 $\beta$ activity and tau is hyperphosphorylated at Ser396, Ser404, and Thr231 [107]. Mitochondrial superoxide activates the mitochondrial fraction of GSK-3 $\alpha / \beta$, resulting in the phosphorylation of the mitochondrial chaperone cyclophilin $D$ [108]. This effect also provides a link between GSK- $3 \beta$ and oxidative stress. Studies have also focused on the link between PP2A and oxidative stress. A recent report shows that rat cortical neurons treated with okadaic acid inhibit PP2A activity, resulting in an abnormal increase in mitochondrial ROS and mitochondrial fission [109]. Other findings reveal that ROS inhibits PP2A and PP5, leading to the activation of JNK and Erk1/2 pathways and subsequently caspasedependent and caspase-independent apoptosis of neuronal cells [110]. Despite these studies, the relationship of GSK3 and PP2A with oxidative stress remains to be further investigated.

3.3.3. Antioxidants and the Tau Protein. Several epidemiological studies have indicated a link between antioxidant intake and reduced incidence of dementia (particularly AD) and cognitive decline in elderly populations [111-113]. In recent years, antioxidant therapy has received considerable attention as a promising approach for slowing the progression of $\mathrm{AD}$. Research has focused on endogenous antioxidants (e.g., vitamins, coenzyme Q10, and melatonin) and the intake of dietary antioxidants, such as phenolic compounds that are flavonoids or nonflavonoids $[114,115]$. This increased interest has thus strengthened the hypothesis that oxidative damage may be responsible for the cognitive and functional decline in $\mathrm{AD}$ patients. Melatonin is a free radical scavenger that blocks tau hyperphosphorylation and microtubule disorganization under in vivo and in vitro conditions [116-118]. It also decreases the activity of GSK-3 $\beta$ [119]. Moreover, melatonin may be a potentially useful agent in the prevention and treatment of $\mathrm{AD}[120]$. Other antioxidants, such as vitamins $\mathrm{E}$ and C [121, 122], gossypin [123], curcumin [124-127], betacarotene [128], and Ginkgo biloba [129, 130], are also reported to have a protective effect against neurotoxicity. In addition, an association also exists between beta-carotene and tau in AD patients [128]. Demethoxycurcumin has been shown to inhibit the phosphorylation of both tau pS(262) and pS(396) in murine neuroblastoma N2A cells [125]. Curcumin also reduces soluble tau and elevated heat shock proteins involved in tau clearance [126]. These results have therefore led to further investigations of this compound as an antioxidant therapy strategy for $\mathrm{AD}$. Other experiments have shown that the active component of Ginkgo biloba, ginkgolide A, inhibits GSK3 $\beta$ and suppressed the phosphorylation level of tau [129].

\section{Autophagy in AD}

4.1. The Autophagic Pathway. Autophagy is an essential lysosomal degradation pathway that turns over cytoplasmic constituents, including misfolded or aggregated proteins and damaged organelles, to facilitate the maintenance of cellular homeostasis [13, 131-134]. Autophagy is usually activated during nutrient deprivation and stress to enhance cellular survival, and its constitutive activity is recognized to control neuronal survival $[14,132,135,136]$. Autophagic dysfunction has been reported to contribute to $\mathrm{AD}[20,64,137,138]$.

Autophagy includes macroautophagy, chaperonemediated autophagy, and microautophagy [13, 132, 134]. The most familiar of these types is macroautophagy, which is a process of cellular self-cannibalism in which portions of the cytoplasm are sequestered within doubleor multimembraned vesicles (autophagosomes) and then delivered to lysosomes for bulk degradation [139]. Autophagy is induced by two pathways in macroautophagy-mammalian target of rapamycin- (mTOR-) dependent and mTORindependent signaling pathways [140]. mTOR is an important convergence point in the cell signaling pathway. mTOR kinase activity is modulated in response to various stimuli, such as trophic factors, mitogens, hormones, amino acids, cell energy status, and cellular stress $[135,136]$. Rapamycin, as mTOR inhibitor, is a very important tool for autophagy [140, 141]. mTOR complex (mTORC) 1 is involved in autophagy and is the master regulator of cell growth enhancing the cellular biomass by upregulating protein translation [142]. For cells to control cellular homoeostasis during growth, a close signaling interplay occurs between mTORCl and two other protein kinases, AMP-activated protein kinase (AMPK) [143] and Unc51-like kinase (ULK1) [144]. Autophagy is inhibited by cytosolic p53 via the direct inhibition of AMPK [145]. mTORC1 controls autophagy by directly interacting with the Ulk1-focal adhesion kinase family-interacting protein of $200 \mathrm{kDa}$ (Atg13-FIP200) complex [146]. Several mTORindependent signals affect the autophagy pathway. When the level of free inositol and myoinositol-1,4,5-trisphosphate IP3 decreases, autophagy is reduced [147]. Furthermore, lower levels of Bcl-2 lead to the release of more Beclin-1, thus forming the Beclin-1-PI3KCIII complex to activate autophagy via the PI3K-AKT-mTOR pathway [148].

4.2. Autophagic Dysfunction in AD Pathology. A growing body of evidence suggests a link between $\mathrm{AD}$ and autophagy 
$[16,17,19,20,22]$. Therefore, the pathological functions of autophagy may be a critical mediator of neurotoxicity [149]. Autophagy develops in $\mathrm{AD}$ brains because of the ineffective degradation of autophagosomes, which is controlled by many kinds of autophagy-related genes (Atg), including Atg1Atg35. Atg8 (mammalian homolog is LC3) is an autophagosomal membrane protein and a marker of autophagosome formation [150]. Beclin-1 (the mammalian ortholog of yeast Atg6) plays a pivotal role in autophagy [151]. In an in vitro study of the pathogenesis of AD, Atg8/LC3 colocalizes with APP and LC3-positive autophagosomes are present [152]. Beclin-1 knockdown increases APP, APP-like proteins, APPC-terminal fragments, and A $\beta$ [153]. Atg5, Atg12, and LC3 are also associated with plaque, tangle pathologies, and neuronal death in $\mathrm{AD}$ [154]. Generally, autophagic vacuoles (AVs) are rare in the normal brain but are increased in brains of $\mathrm{AD}$ patients. In the early stages of $\mathrm{AD}$, the expression of lysosome-related component is significantly increased prior to the formation of plaques and NFTs, and autophagy is also induced at this stage; thus its activity is independent of extracellular $\mathrm{A} \beta$ deposition and NFT formation [155]. In the late stage of $\mathrm{AD}, \mathrm{AVs}$ continue to accumulate in large numbers in dystrophic neurites. There are several causes for the dysfunction of autophagy in late-stage $\mathrm{AD}$, including the enhanced processing of APP and A $\beta$ degradation [156] and the toxic effect of high levels of intracellular $A \beta$ on lysosomal function [157]. Inhibition of the AV-lysosome fusion is caused by impaired microtubule-associated retrograde transport, which in turn leads to increased accumulation of AV in dystrophic neurites [134]. Lysosomal enzyme dysfunction may be associated with the accumulation of AVs [158]. Autophagy plays an important role in the degradation of impaired mitochondria in $\mathrm{AD}[158,159]$. Dysfunction of the autophagy-lysosome system causes insufficient degradation of mitochondria [160]. Conversely, mitochondrial dysfunction may also impair this pathway [161].

\subsection{Autophagy and the Tau Protein}

4.3.1. Tau Protein Degradation via Autophagy. A variety of forms of tau proteins have been shown to be degraded by the ubiquitin-proteasome system (UPS) and autophagylysosome system. UPS may play an important role in the primary clearance of pathological tau. However, the importance of autophagy-mediated tau degradation, particularly at the late stage of NFT formation, is becoming more recognized. The autophagy-lysosomal system has the capacity to engulf protein aggregates and keep tau levels at a low level [162]. Macroautophagy is believed to be an evolutionarily conserved mechanism for intracellular degradation of proteins, such as $A \beta$ and tau. mTOR in negatively regulating autophagy is an important convergence point in cell signaling. Increasing mTOR signaling and PI3K/AKT/mTOR pathway facilitates tau pathology, but reducing this signaling ameliorates tau pathology $[11,20,163]$. Rapamycin has been reported to decrease tau phosphorylation at Ser214 in vitro and reduce tau tangles and insoluble tau in vivo $[164,165]$. In a tetracycline-inducible model $[\operatorname{tauDeltaC}(\operatorname{tau} \Delta \mathrm{C})]$, tau is abnormally truncated at $\mathrm{Asp}^{421}$ and is cleared predominantly by macroautophagy and degraded significantly faster than full-length tau [166]. Autophagy activation suppresses tau aggregation and eliminates cytotoxicity [163]. Moreover, trehalose (an enhancer of autophagy) directly inhibits tau aggregation in primary neurons [167]. Under in vitro conditions, the accumulation of tau species is increased with the autophagic inhibitor, 3-methyladenine, and decreased with trehalose [168]. Overall, these results suggest that tau degradation involves autophagy, and this activity is beneficial for neurons to prevent the accumulation of protein aggregates.

\subsubsection{Tau Protein Hyperphosphorylation Leads to Autophagic} Dysfunction. The physiological function of tau protein is well known to be associated with microtubule binding and assembly. Autophagosome transport mainly depends on the movement along microtubules in the autophagic pathway. However, the link between tau hyperphosphorylation and autophagic dysfunction is still under debate. Frontotemporal dementia and parkinsonism linked to chromosome 17(FTDP-17-) mediated tau mutations can disrupt lysosomal function in transgenic mice expressing human tau with four tubulin-binding repeats (increased by FTDP-17 splice donor mutations) and three FTDP-17 missense mutations: G272V, P301L, and R406W [169]. In Tg mice expressing mutant human (P301L) tau, axonal spheroids have been shown to contain tau-immunoreactive filaments and AVs [170]. A recent study has revealed that PP2A upregulation stimulates neuronal autophagy, thus providing a link between PP2A downregulation, autophagy disruption, and protein aggregation [171]. Furthermore, autophagosomes have been shown to be increased in rat neurons treated with okadaic acid [172]. Altogether, tau is known to regulate the stability of microtubules, and tau hyperphosphorylation may result in the destabilization of neuronal microtubules, thus affecting the placement and function of mitochondria and lysosomes. Therefore, tau hyperphosphorylation is likely to play a critical role in the process of autophagic dysfunction.

4.3.3. Autophagic Dysfunction Induces Tau Protein Aggregation and Neurodegeneration. The autophagy-lysosome system is well recognized to play an important role in the clearance of abnormally modified proteins in cells. Several studies have shown that dysfunction of the autophagy-lysosome system contributes to the formation of tau oligomers and insoluble aggregates [22, 173, 174]. Abnormal lysosomal proteases are also found in brains of AD patients $[173,174]$. Both phosphorylated tau and GSK3 $\beta$ significantly accumulate in Atg7 conditional knockout brains, although NFTs are absent [20]. The hyperphosphorylation of tau and NFT formation result in the disruption of the neuronal skeleton, thereby contributing to neuronal dysfunction, cell death, and eventually the symptoms of $\mathrm{AD}$. Genetic reduction of mammalian target of rapamycin led to an increase in autophagy induction and ameliorates Alzheimer's disease-like cognitive and pathological deficits [22]. Induction autophagy adaptor protein NDP52 may reduce tau protein phosphorylation in neurons [20]. Therefore, the autophagy-lysosome system plays a crucial role 


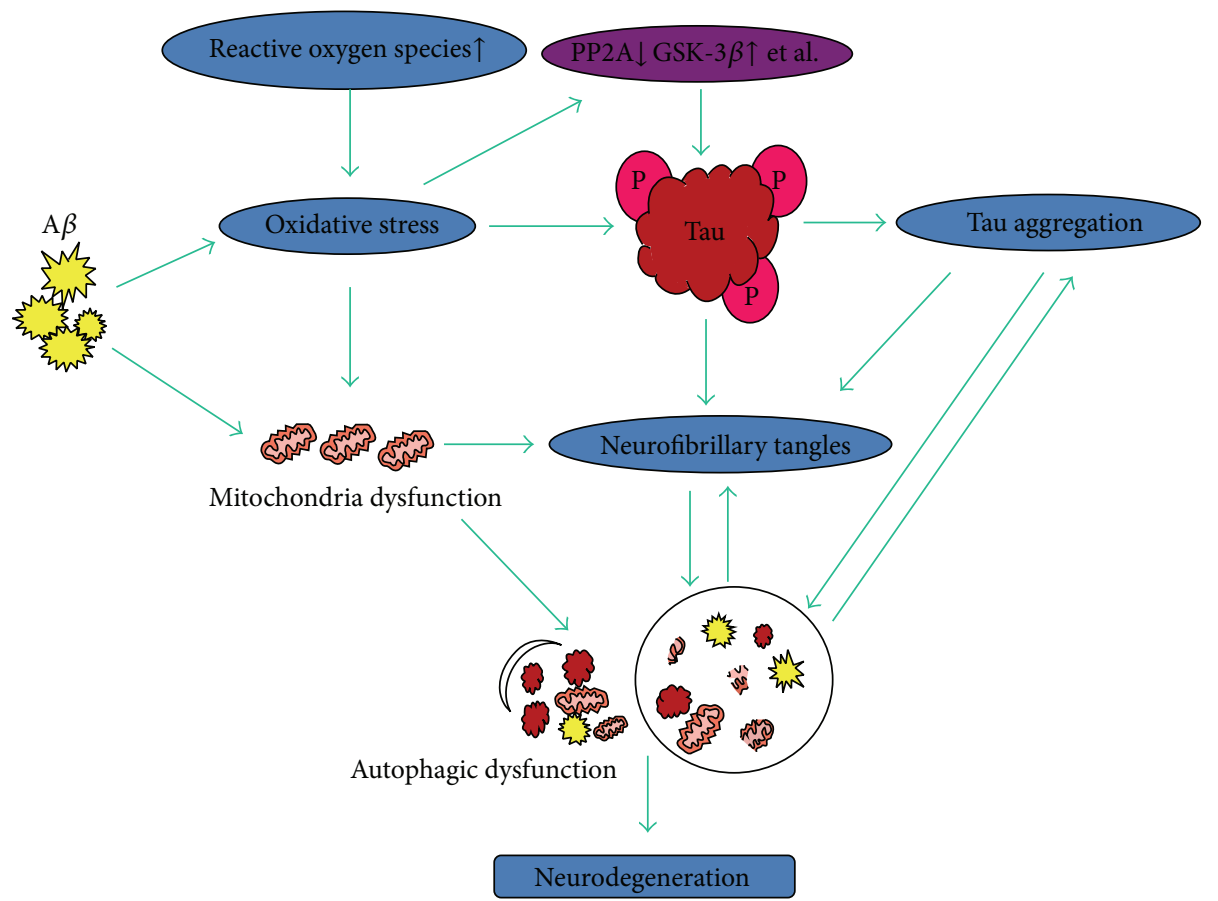

FIGURE 1: Tau protein NFTs formation and autophagic dysfunction in Alzheimer's disease. A $\beta$ oligomers and ROS production intrigue oxidative stress and mitochondria dysfunction, in which induce tau protein hyperphosphorylation and neurofibrillary tangles formation with protein phosphatase and kinases imbalance. These events converge to autophagic dysfunction and tau protein aggregation to lead to neurodegeneration and cell death in AD.

in the clearance of tau, and its accumulation may be due to autophagic dysfunction in cells.

\section{Conclusion}

Oxidative stress is reported to be one of the earliest events in $\mathrm{AD}$ and can induce tau hyperphosphorylation, which destabilizes microtubules by decreasing the binding affinity of tau, thereby resulting in the formation of NFTs, which are a major pathological hallmark of $\mathrm{AD} . \mathrm{A} \beta$ and other risk factors play the crucial role in neuronal oxidative stress. A $\beta$ mediated mitochondrial oxidative stress causes hyperphosphorylation of tau in $\mathrm{AD}$ brains, as well as mitochondrial dysfunction. Tau hyperphosphorylation may be the necessary point in neural dysfunction and death. Hyperphosphorylation, oligomerization, fibrillization, and propagation of tau pathology have been proposed as the pathogenesis of taumediated neurodegeneration. In addition to oxidative stress, tau protein phosphorylation is also regulated by protein kinase and phosphatase. It indicates the roles of mitochondria and protein phosphatase on oxidative stress and tau protein hyperphosphorylation. Meanwhile it strengthens the hypothesis that oxidative damage is responsible for the cognitive and functional decline in $\mathrm{AD}$ patients.

Dysfunctional tau protein is degraded via autophagylysosomal pathway. Autophagy is an essential lysosomal degradation process that turns over cytoplasmic constituents, including misfolded or aggregated proteins and damaged organelles, to facilitate the maintenance of cellular homeostasis. Tau hyperphosphorylation is likely to play a critical role in the process of autophagic dysfunction, and dysfunction of the autophagy-lysosome system may also promote the tau aggregation. Altogether, tau is known to regulate the stability of microtubules, and tau hyperphosphorylation may result in the destabilization of neuronal microtubules, thus affecting the function of mitochondria and lysosomes.

These events initiate a series of cascades to induce neurodegeneration and cell death in $\mathrm{AD} . \mathrm{A} \beta$ oligomers and ROS production intrigue oxidative stress and mitochondria dysfunction, in which they induce tau protein hyperphosphorylation and neurofibrillary tangles formation with protein phosphatase and kinases imbalance. These events converge to autophagic dysfunction and tau protein aggregation to lead to neurodegeneration and cell death in AD (Figure 1). However, the relationships between oxidative stress, tau hyperphosphorylation, and autophagic dysfunction and accurate mechanisms on neurodegeneration, especially mitochondria and protein phosphatase in $\mathrm{AD}$, still require further research.

\section{Conflict of Interests}

The authors have no conflict of interests to declare.

\section{Authors' Contribution}

Zhenzhen Liu, Tao Li, and Ping Li equally contributed to this study. 


\section{Acknowledgments}

This work is supported by National Natural Science Foundation of China Grants 81271410 (Jianshe Wei) and 81471174 (Mengzhou Xue). Drs. Wei and Xue are Yellow River Scholars in neurobiology and neurology.

\section{References}

[1] T. Cumming and A. Brodtmann, "Dementia and stroke: the present and future epidemic," International Journal of Stroke, vol. 5, no. 6, pp. 453-454, 2010.

[2] S. W.-C. Chan, "Family caregiving in dementia: the asian perspective of a global problem," Dementia and Geriatric Cognitive Disorders, vol. 30, no. 6, pp. 469-478, 2011.

[3] R. A. Armstrong, "A critical analysis of the 'amyloid cascade hypothesis"' Folia Neuropathologica, vol. 52, no. 3, pp. 211-225, 2014.

[4] K. L. Viola and W. L. Klein, "Amyloid $\beta$ oligomers in Alzheimer's disease pathogenesis, treatment, and diagnosi," Acta Neuropathologica, vol. 129, no. 2, pp. 183-206, 2015.

[5] A. C. Paula-Lima, J. Brito-Moreira, and S. T. Ferreira, "Deregulation of excitatory neurotransmission underlying synapse failure in Alzheimer's disease," Journal of Neurochemistry, vol. 126, no. 2, pp. 191-202, 2013.

[6] A. K. Y. Fu, K.-W. Hung, H. Huang et al., "Blockade of EphA4 signaling ameliorates hippocampal synaptic dysfunctions in mouse models of Alzheimer's disease," Proceedings of the National Academy of Sciences of the United States of America, vol. 111, no. 27, pp. 9959-9964, 2014.

[7] F. G. De Felice, P. T. Velasco, M. P. Lambert et al., "A $\beta$ oligomers induce neuronal oxidative stress through an N-methyl-Daspartate receptor-dependent mechanism that is blocked by the Alzheimer drug memantine," The Journal of Biological Chemistry, vol. 282, no. 15, pp. 11590-11601, 2007.

[8] S. Melov, P. A. Adlard, K. Morten et al., "Mitochondrial oxidative stress causes hyperphosphorylation of tau," PLoS ONE, vol. 2, no. 6, Article ID e536, 2007.

[9] B. Su, X. Wang, H. G. Lee et al., "Chronic oxidative stress causes increased tau phosphorylation in M17 neuroblastoma cells," Neuroscience Letters, vol. 468, no. 3, pp. 267-271, 2010.

[10] D. Luque-Contreras, K. Carvajal, D. Toral-Rios, D. FrancoBocanegra, and V. Campos-Peña, "Oxidative stress and metabolic syndrome: cause or consequence of Alzheimer's disease?" Oxidative Medicine and Cellular Longevity, vol. 2014, Article ID 497802, 11 pages, 2014.

[11] D. Heras-Sandoval, J. M. Pérez-Rojas, J. Hernández-Damián, and J. Pedraza-Chaverri, "The role of PI3K/AKT/mTOR pathway in the modulation of autophagy and the clearance of protein aggregates in neurodegeneration," Cellular Signalling, vol. 26, no. 12, pp. 2694-2701, 2014.

[12] Y. Saitoh, N. Fujikake, Y. Okamoto et al., "p62 plays a protective role in the autophagic degradation of polyglutamine protein oligomers in polyglutamine disease model flies," Journal of Biological Chemistry, vol. 290, no. 3, pp. 1442-1453, 2015.

[13] S. Ghavami, S. Shojaei, B. Yeganeh et al., "Autophagy and apoptosis dysfunction in neurodegenerative disorders," Progress in Neurobiology, vol. 112, pp. 24-49, 2014.

[14] C.-C. Tan, J.-T. Yu, M.-S. Tan, T. Jiang, X.-C. Zhu, and L. Tan, "Autophagy in aging and neurodegenerative diseases: implications for pathogenesis and therapy," Neurobiology of Aging, vol. 35, no. 5, pp. 941-957, 2014.
[15] A. Salminen, K. Kaarniranta, A. Kauppinen et al., "Impaired autophagy and APP processing in Alzheimer's disease: the potential role of Beclin 1 interactome," Progress in Neurobiology, vol. 106-107, pp. 33-54, 2013.

[16] D.-S. Yang, P. Stavrides, M. Saito et al., "Defective macroautophagic turnover of brain lipids in the TgCRND8 Alzheimer mouse model: prevention by correcting lysosomal proteolytic deficits," Brain, vol. 137, part 12, pp. 3300-3318, 2014.

[17] P. Nilsson, M. Sekiguchi, T. Akagi et al., "Autophagy-related protein 7 deficiency in amyloid $\beta(A \beta)$ precursor protein transgenic mice decreases $A \beta$ in the multivesicular bodies and induces $A \beta$ accumulation in the Golgi," The American Journal of Pathology, vol. 185, no. 2, pp. 305-313, 2015.

[18] D. M. Wolfe, J.-H. Lee, A. Kumar, S. Lee, S. J. Orenstein, and R. A. Nixon, "Autophagy failure in Alzheimer's disease and the role of defective lysosomal acidification," European Journal of Neuroscience, vol. 37, no. 12, pp. 1949-1961, 2013.

[19] Y. Tian, J. C. Chang, E. Y. Fan, M. Flajolet, and P. Greengard, "Adaptor complex AP2/PICALM, through interaction with LC3, targets Alzheimer's APP-CTF for terminal degradation via autophagy," Proceedings of the National Academy of Sciences of the United States of America, vol. 110, no. 42, pp. 17071-17076, 2013.

[20] C. Jo, S. Gundemir, S. Pritchard, Y. N. Jin, I. Rahman, and G. V. W. Johnson, "Nrf2 reduces levels of phosphorylated tau protein by inducing autophagy adaptor protein NDP52," Nature Communications, vol. 5, article 3496, 2014.

[21] T. Lu, L. Aron, J. Zullo et al., "REST and stress resistance in ageing and Alzheimer's disease," Nature, vol. 507, no. 7493, pp. 448-454, 2014.

[22] A. Caccamo, V. De Pinto, A. Messina, C. Branca, and S. Oddo, "Genetic reduction of mammalian target of rapamycin ameliorates Alzheimer's disease-like cognitive and pathological deficits by restoring hippocampal gene expression signature," Journal of Neuroscience, vol. 34, no. 23, pp. 7988-7998, 2014.

[23] E. Martínez, A. Navarro, C. Ordóñez, E. del Valle, and J. Tolivia, "Oxidative stress induces apolipoprotein D overexpression in hippocampus during aging and alzheimer's disease," Journal of Alzheimer's Disease, vol. 36, no. 1, pp. 129-144, 2013.

[24] Y. Zhao and B. Zhao, "Oxidative stress and the pathogenesis of alzheimer's disease," Oxidative Medicine and Cellular Longevity, vol. 2013, Article ID 316523, 10 pages, 2013.

[25] J. M. Flynn and S. Melovn, "SOD2 in mitochondrial dysfunction and neurodegeneration," Free Radical Biology and Medicine, vol. 62, pp. 4-12, 2013.

[26] A. K. Holley, V. Bakthavatchalu, J. M. Velez-Roman, and D. K. St. Clair, "Manganese superoxide dismutase: guardian of the powerhouse," International Journal of Molecular Sciences, vol. 12, no. 10, pp. 7114-7162, 2011.

[27] M. P. Mattson and T. Magnus, "Ageing and neuronal vulnerability," Nature Reviews Neuroscience, vol. 7, no. 4, pp. 278-294, 2006.

[28] L. Chen, R. Na, and Q. Ran, "Enhanced defense against mitochondrial hydrogen peroxide attenuates age-associated cognition decline," Neurobiology of Aging, vol. 35, no. 11, pp. 2552-2561, 2014.

[29] D. Yamazaki, J. Horiuchi, K. Ueno et al., "Glial dysfunction causes age-related memory impairment in Drosophila," Neuron, vol. 84, no. 4, pp. 753-763, 2014.

[30] H. Tayler, T. Fraser, J. S. Miners, P. G. Kehoe, and S. Love, "Oxidative balance in Alzheimer's disease: relationship to 
APOE, braak tangle stage, and the concentrations of soluble and insoluble amyloid- $\beta$," Journal of Alzheimer's Disease, vol. 22, no. 4, pp. 1363-1373, 2010.

[31] B. H. Han, M. L. Zhou, A. W. Johnson et al., "Contribution of reactive oxygen species to cerebral amyloid angiopathy, vasomotor dysfunction, and microhemorrhage in aged Tg2576 mice," Proceedings of The National Academy of Sciences of The United States of America, vol. 112, no. 8, pp. E881-E890, 2015.

[32] P. Nordström, K. Michaëlsson, Y. Gustafson, and A. Nordström, "Traumatic brain injury and young onset dementia: a nationwide cohort study," Annals of Neurology, vol. 75, no. 3, pp. 374381, 2014.

[33] J. Zhou, J. T. Yu, H. F. Wang et al., "Association between stroke and Alzheimer's disease: systematic review and meta-analysis," Journal of Alzheimers Disease, vol. 43, no. 2, pp. 479-489, 2015.

[34] D. Cifuentes, M. Poittevin, E. Dere et al., "Hypertension accelerates the progression of Alzheimer-like pathology in a mouse model of the disease," Hypertension, vol. 65, no. 1, pp. 218-224, 2015.

[35] M. Barbagallo and L. J. Dominguez, "Type 2 diabetes mellitus and Alzheimer's disease," The World Journal of Diabetes, vol. 5, no. 6, pp. 889-893, 2014.

[36] S. H. Park, J. H. Kim, K. H. Choi et al., "Hypercholesterolemia accelerates amyloid $\beta$-induced cognitive deficits," International Journal of Molecular Medicine, vol. 31, no. 3, pp. 577-582, 2013.

[37] K. Nazef, M. Khelil, H. Chelouti et al., "Hyperhomocysteinemia is a risk factor for Alzheimer's disease in an Algerian population," Archives of Medical Research, vol. 45, no. 3, pp. 247-250, 2014.

[38] N. VanDuyn, R. Settivari, J. LeVora, S. Zhou, J. Unrine, and R. Nass, "The metal transporter SMF-3/DMT-1 mediates aluminum-induced dopamine neuron degeneration," Journal of Neurochemistry, vol. 124, no. 1, pp. 147-157, 2013.

[39] T. C. Durazzo, N. Mattsson, and M. W. Weiner, "Smoking and increased Alzheimer's disease risk: a review of potential mechanisms," Alzheimers and Dementia, vol. 10, no. 3, pp. S122S145, 2014.

[40] G. M. Pasinetti and J. A. Eberstein, "Metabolic syndrome and the role of dietary lifestyles in Alzheimer's disease," Journal of Neurochemistry, vol. 106, no. 4, pp. 1503-1514, 2008.

[41] T. J. Littlejohns, W. E. Henley, I. A. Lang et al., "Vitamin D and the risk of dementia and Alzheimer disease," Neurology, vol. 83, no. 10, pp. 920-928, 2014.

[42] O. Ohia-Nwoko, S. Montazari, Y.-S. Lau, and J. L. Eriksen, "Long-term treadmill exercise attenuates tau pathology in P301S tau transgenic mice," Molecular Neurodegeneration, vol. 9, article 54, 2014.

[43] A. Nunomura, R. J. Castellani, X. Zhu, P. I. Moreira, G. Perry, and M. A. Smith, "Involvement of oxidative stress in Alzheimer disease," Journal of Neuropathology \& Experimental Neurology, vol. 65, no. 7, pp. 631-641, 2006.

[44] P. Vemuri, T. G. Lesnick, S. A. Przybelski et al., "Effect of lifestyle activities on alzheimer disease biomarkers and cognition," Annals of Neurology, vol. 72, no. 5, pp. 730-738, 2012.

[45] M. Antoniou, G. M. Gunasekera, and P. C. M. Wong, "Foreign language training as cognitive therapy for age-related cognitive decline: a hypothesis for future research," Neuroscience and Biobehavioral Reviews, vol. 37, part 2, pp. 2689-2698, 2013.

[46] J. Yao, R. W. Irwin, L. Zhao, J. Nilsen, R. T. Hamilton, and R. D. Brinton, "Mitochondrial bioenergetic deficit precedes Alzheimer's pathology in female mouse model of Alzheimer's disease," Proceedings of the National Academy of Sciences of the United States of America, vol. 106, no. 34, pp. 14670-14675, 2009.

[47] V. García-Escudero, P. Martín-Maestro, G. Perry, and J. Avila, "Deconstructing mitochondrial dysfunction in alzheimer disease," Oxidative Medicine and Cellular Longevity, vol. 2013, Article ID 162152, 13 pages, 2013.

[48] S. Mondragón-Rodríguez, G. Perry, X. Zhu, P. I. Moreira, M. C. Acevedo-Aquino, and S. Williams, "Phosphorylation of tau protein as the link between oxidative stress, mitochondrial dysfunction, and connectivity failure: implications for Alzheimer's disease," Oxidative Medicine and Cellular Longevity, vol. 2013, Article ID 940603, 6 pages, 2013.

[49] J. Yao, H. Du, S. Yan et al., "Inhibition of amyloid-beta (Abeta) peptide-binding alcohol dehydrogenase-Abeta interaction reduces Abeta accumulation and improves mitochondrial function in a mouse model of Alzheimer's disease," Journal of Neuroscience, vol. 31, no. 6, pp. 2313-2320, 2011.

[50] A. Pensalfini, M. Zampagni, G. Liguri et al., "Membrane cholesterol enrichment prevents $\mathrm{A} \beta$-induced oxidative stress in Alzheimer's fibroblasts," Neurobiology of Aging, vol. 32, no. 2, pp. 210-222, 2011.

[51] K. Schuessel, S. Schäfer, T. A. Bayer et al., "Impaired Cu/ZnSOD activity contributes to increased oxidative damage in APP transgenic mice," Neurobiology of Disease, vol. 18, no. 1, pp. 8999, 2005.

[52] M. Dumont, C. Stack, C. Elipenahli et al., "Behavioral deficit, oxidative stress, and mitochondrial dysfunction precede tau pathology in P301S transgenic mice," The FASEB Journal, vol. 25, no. 11, pp. 4063-4072, 2011.

[53] K. Murakami, N. Murata, Y. Noda et al., "SOD1 (copper/zinc superoxide dismutase) deficiency drives amyloid $\beta$ protein oligomerization and memory loss in mouse model of Alzheimer disease," The Journal of Biological Chemistry, vol. 286, no. 52, pp. 44557-44568, 2011.

[54] D. Poppek, S. Keck, G. Ermak et al., "Phosphorylation inhibits turnover of the tau protein by the proteasome: influence of RCAN1 and oxidative stress," Biochemical Journal, vol. 400, no. 3, pp. 511-520, 2006.

[55] S. Melov, P. A. Adlard, K. Morten et al., "Mitochondrial oxidative stress causes hyperphosphorylation of tau," PLOS ONE, vol. 2, no. 6, article e536, 2007.

[56] T. Morita and K. Sobuě, "Specification of neuronal polarity regulated by local translation of CRMP2 and tau via the mTORp70S6K pathway," Journal of Biological Chemistry, vol. 284, no. 40, pp. 27734-27745, 2009.

[57] L. Li, T. Fothergill, B. I. Hutchins, E. W. Dent, and K. Kalil, "Wnt5a evokes cortical axon outgrowth and repulsive guidance by tau mediated reorganization of dynamic microtubules," Developmental Neurobiology, vol. 74, no. 8, pp. 797-817, 2014.

[58] A. Fuster-Matanzo, M. Llorens-Martín, J. Jurado-Arjona, J. Avila, and F. Hernández, "Tau protein and adult hippocampal neurogenesis," Frontiers in Neuroscience, vol. 6, article 104, 2012.

[59] J. Avila, J. J. Lucas, M. Pérez, and F. Hernández, "Role of Tau protein in both physiological and pathological conditions," Physiological Reviews, vol. 84, no. 2, pp. 361-384, 2004.

[60] D. Gordon, G. J. Kidd, and R. Smith, "Antisense suppression of tau in cultured rat oligodendrocytes inhibits process formation," Journal of Neuroscience Research, vol. 86, no. 12, pp. 2591-2601, 2008.

[61] M. Kolarova, F. García-Sierra, A. Bartos, J. Ricny, and D. Ripova, "Structure and pathology of tau protein in Alzheimer disease," 
International Journal of Alzheimer's Disease, vol. 2012, Article ID 731526, 13 pages, 2012.

[62] C. Fauquant, V. Redeker, I. Landrieu et al., "Systematic identification of tubulin-interacting fragments of the microtubuleassociated protein Tau leads to a highly efficient promoter of microtubule assembly," Journal of Biological Chemistry, vol. 286, no. 38, pp. 33358-33368, 2011.

[63] H.-L. Li, H.-H. Wang, S.-J. Liu et al., "Phosphorylation of tau antagonizes apoptosis by stabilizing beta-catenin, a mechanism involved in Alzheimer's neurodegeneration," Proceedings of the National Academy of Sciences of the United States of America, vol. 104, no. 9, pp. 3591-3596, 2007.

[64] T. Rodríguez-Martín, I. Cuchillo-Ibáñez, W. Noble, F. Nyenya, B. H. Anderton, and D. P. Hanger, "Tau phosphorylation affects its axonal transport and degradation," Neurobiology of Aging, vol. 34, no. 9, pp. 2146-2157, 2013.

[65] C. Ballatore, K. R. Brunden, D. M. Huryn, J. Q. Trojanowski, V. M.-Y. Lee, and A. B. Smith, "Microtubule stabilizing agents as potential treatment for Alzheimer's disease and related neurodegenerative tauopathies," Journal of Medicinal Chemistry, vol. 55, no. 21, pp. 8979-8996, 2012.

[66] D. Simón, E. García-García, F. Royo, J. M. Falcón-Pérez, and J. Avila, "Proteostasis of tau. Tau overexpression results in its secretion via membrane vesicles," FEBS Letters, vol. 586, no. 1 , pp. 47-54, 2012.

[67] W. Qian and F. Liu, "Regulation of alternative splicing of tau exon 10," Neuroscience Bulletin, vol. 30, no. 2, pp. 367-377, 2014.

[68] F. Liu and C.-X. Gong, "Tau exon 10 alternative splicing and tauopathies," Molecular Neurodegeneration, vol. 3, no. 1, article 8,2008 .

[69] N. Jovanov-Milošević, D. Petrović, G. Sedmak, M. Vukšić, P. R. Hof, and G. Šimić, "Human fetal tau protein isoform: possibilities for Alzheimer's disease treatment," The International Journal of Biochemistry \& Cell Biology, vol. 44, no. 8, pp. 1290-1294, 2012.

[70] S. J. Adams, M. A. de Ture, M. McBride, D. W. Dickson, and L. Petrucelli, "Three repeat isoforms of tau inhibit assembly of four repeat tau filaments," PLoS ONE, vol. 5, no. 5, Article ID e10810, 2010.

[71] M. Espinoza, R. de Silva, D. W. Dickson, and P. Davies, "Differential incorporation of tau isoforms in Alzheimer's disease," Journal of Alzheimer's Disease, vol. 14, no. 1, pp. 1-16, 2008.

[72] M. Fernández-Nogales, J. R. Cabrera, M. Santos-Galindo et al., "Huntington's disease is a four-repeat tauopathy with tau nuclear rods," Nature Medicine, vol. 20, no. 8, pp. 881-885, 2014.

[73] D. C. Glatz, D. Rujescu, Y. Tang et al., “The alternative splicing of tau exon 10 and its regulatory proteins CLK2 and TRA2BETA1 changes in sporadic Alzheimer's disease," Journal of Neurochemistry, vol. 96, no. 3, pp. 635-644, 2006.

[74] M. J. Niblock and J. M. Gallo, "Tau alternative splicing in familial and sporadic tauopathies," Biochemical Society Transactions, vol. 40, no. 4, pp. 677-680, 2012.

[75] Y. Yoshiyama, V. M. Y. Lee, and J. Q. Trojanowski, “Therapeutic strategies for tau mediated neurodegeneration," Journal of Neurology, Neurosurgery \& Psychiatry, vol. 84, no. 7, pp. 784795, 2013.

[76] K. Iijima-Ando, L. Zhao, A. Gatt, C. Shenton, and K. Iijima, "A DNA damage-activated checkpoint kinase phosphorylates tau and enhances tau-induced neurodegeneration," Human Molecular Genetics, vol. 19, no. 10, pp. 1930-1938, 2010.
[77] J. Mendoza, M. Sekiya, T. Taniguchi, K. M. Iijima, R. Wang, and K. Ando, "Global analysis of phosphorylation of Tau by the checkpoint kinases Chk1 and Chk2 in vitro," Journal of Proteome Research, vol. 12, no. 6, pp. 2654-2665, 2013.

[78] S. Flunkert, M. Hierzer, T. Löffler et al., "Elevated levels of soluble total and hyperphosphorylated tau result in early behavioral deficits and distinct changes in brain pathology in a new tau transgenic mouse model," American Journal of Neurodegenerative Disease, vol. 11, no. 4, pp. 194-205, 2013.

[79] C.-X. Gong and K. Iqbal, "Hyperphosphorylation of microtubule-associated protein tau: a promising therapeutic target for Alzheimer disease," Current Medicinal Chemistry, vol. 15, no. 23, pp. 2321-2328, 2008.

[80] E. Kiris, D. Ventimiglia, M. E. Sargin et al., "Combinatorial Tau pseudophosphorylation: markedly different regulatory effects on microtubule assembly and dynamic instability than the sum of the individual parts," The Journal of Biological Chemistry, vol. 286, no. 16, pp. 14257-14270, 2011.

[81] F. Hernandez, J. J. Lucas, and J. Avila, "GSK3 and tau: two convergence points in Alzheimer's disease," Journal of Alzheimer's Disease, vol. 33, no. 1, pp. S141-S144, 2013.

[82] C. Gao, C. Hölscher, Y. Liu, and L. Li, "GSK3: a key target for the development of novel treatments for type 2 diabetes mellitus and Alzheimer disease," Reviews in the Neurosciences, vol. 23, no. 1, pp. 1-11, 2011.

[83] J. C. Gandy, M. Melendez-Ferro, G. N. Bijur et al., "Glycogen synthase kinase-3 $\beta$ (GSK3 $\beta$ ) expression in a mouse model of Alzheimer's disease: a light and electron microscopy study," Synapse, vol. 67, no. 6, pp. 313-327, 2013.

[84] H. Maldonado, E. Ramírez, E. Utreras et al., "Inhibition of cyclin-dependent kinase 5 but not of glycogen synthase kinase $3-\beta$ prevents neurite retraction and tau hyperphosphorylation caused by secretable products of human T-cell leukemia virus type I-infected lymphocytes," Journal of Neuroscience Research, vol. 89, no. 9, pp. 1489-1498, 2011.

[85] A. López-Tobón, J. F. Castro-Álvarez, D. Piedrahita, R. L. Boudreau, J. C. Gallego-Gómez, and G. P. Cardona-Gómez, "Silencing of CDK5 as potential therapy for Alzheimer's disease," Reviews in the Neurosciences, vol. 22, no. 2, pp. 143-152, 2011.

[86] S. A. L. Corrêa and K. L. Eales, "The role of p38 MAPK and its substrates in neuronal plasticity and neurodegenerative disease," Journal of Signal Transduction, vol. 2012, Article ID 649079, 12 pages, 2012.

[87] G. Li, H. Yin, and J. Kuret, "Casein kinase 1 delta phosphorylates tau and disrupts its binding to microtubules," Journal of Biological Chemistry, vol. 279, no. 16, pp. 15938-15945, 2004.

[88] F. Liu, Z. Liang, J. Shi et al., "PKA modulates GSK-3 $\beta$ - and cdk5catalyzed phosphorylation of tau in site- and kinase-specific manners," FEBS Letters, vol. 580, no. 26, pp. 6269-6274, 2006.

[89] M. Tsukane and T. Yamauchi, " $\mathrm{Ca}^{2+} /$ calmodulin-dependent protein kinase II mediates apoptosis of P19 cells expressing human tau during neural differentiation with retinoic acid treatment," Journal of Enzyme Inhibition and Medicinal Chemistry, vol. 24, no. 2, pp. 365-371, 2009.

[90] F. Liu, I. Grundke-Iqbal, K. Iqbal, and C.-X. Gong, "Contributions of protein phosphatases PP1, PP2A, PP2B and PP5 to the regulation of tau phosphorylation," European Journal of Neuroscience, vol. 22, no. 8, pp. 1942-1950, 2005.

[91] I. Landrieu, C. Smet-Nocca, L. Amniai et al., "Molecular implication of PP2A and Pin1 in the Alzheimer's disease specific 
hyperphosphorylation of Tau," PLoS ONE, vol. 6, no. 6, Article ID e21521, 2011.

[92] P. Rudrabhatla and H. C. Pant, "Role of protein phosphatase $2 \mathrm{~A}$ in Alzheimer's disease," Current Alzheimer Research, vol. 8, no. 6, pp. 623-632, 2011.

[93] S. S. Park, H.-J. Jung, Y.-J. Kim et al., "Asp664 cleavage of amyloid precursor protein induces tau phosphorylation by decreasing protein phosphatase 2A activity," Journal of Neurochemistry, vol. 123, no. 5, pp. 856-865, 2012.

[94] Z. Liang, F. Liu, K. Iqbal, I. Grundke-Iqbal, J. Wegiel, and C. X. Gong, "Decrease of protein phosphatase 2A and its association with accumulation and hyperphosphorylation of tau in Down syndrome," Journal of Alzheimer's Disease, vol. 13, no. 3, pp. 295$302,2008$.

[95] L. Martin, X. Latypova, C. M. Wilson, A. Magnaudeix, M.-L. Perrin, and F. Terro, "Tau protein phosphatases in Alzheimer's disease: the leading role of PP2A," Ageing Research Reviews, vol. 12, no. 1, pp. 39-49, 2013.

[96] M. Arif, J. Wei, Q. Zhang et al., "Cytoplasmic retention of protein phosphatase 2A-inhibitor 2 (I2PP2A) induces Alzheimerlike abnormal hyperphosphorylation of Tau," The Journal of Biological Chemistry, vol. 289, no. 40, pp. 27677-27691, 2014.

[97] L. Arnaud, S. Chen, F. Liu et al., "Mechanism of inhibition of PP2A activity and abnormal hyperphosphorylation of tau by I2(PP2A)/SET,' FEBS Letters, vol. 585, no. 17, pp. 2653-2659, 2011.

[98] G.-P. Liu, Y. Zhang, X.-Q. Yao et al., "Activation of glycogen synthase kinase-3 inhibits protein phosphatase-2A and the underlying mechanisms," Neurobiology of Aging, vol. 29, no. 9, pp. 1348-1358, 2008.

[99] P. K. Kamat, S. Rai, and C. Nath, "Okadaic acid induced neurotoxicity: an emerging tool to study Alzheimer's disease pathology," NeuroToxicology, vol. 37, pp. 163-172, 2013.

[100] S. Patil and C. Chan, "Palmitic and stearic fatty acids induce Alzheimer-like hyperphosphorylation of tau in primary rat cortical neurons," Neuroscience Letters, vol. 384, no. 3, pp. 288293, 2005.

[101] M. A. Lovell, S. Xiong, C. Xie, P. Davies, and W. R. Markesbery, "Induction of hyperphosphorylated tau in primary rat cortical neuron cultures mediated by oxidative stress and glycogen synthase kinase-3," Journal of Alzheimer's Disease, vol. 6, no. 6, pp. 659-671, 2004.

[102] C. A. Zambrano, J. T. Egaña, M. T. Núñez, R. B. Maccioni, and C. González-Billault, "Oxidative stress promotes $\tau$ dephosphorylation in neuronal cells: the roles of cdk5 and PP1," Free Radical Biology and Medicine, vol. 36, no. 11, pp. 1393-1402, 2004.

[103] D. Dias-Santagata, T. A. Fulga, A. Duttaroy, and M. B. Feany, "Oxidative stress mediates tau-induced neurodegeneration in Drosophila," The Journal of Clinical Investigation, vol. 117, no. 1, pp. 236-245, 2007.

[104] B. Frost, M. Hemberg, J. Lewis, and M. B. Feany, "Tau promotes neurodegeneration through global chromatin relaxation," Nature Neuroscience, vol. 17, no. 3, pp. 357-366, 2014.

[105] V. Khurana, "Modeling tauopathy in the fruit fly Drosophila melanogaster," Journal of Alzheimer's Disease, vol. 15, no. 4, pp. 541-553, 2008.

[106] X.-Y. Su, W.-H. Wu, Z.-P. Huang et al., "Hydrogen peroxide can be generated by tau in the presence of $\mathrm{Cu}(\mathrm{II})$, , Biochemical and Biophysical Research Communications, vol. 358, no. 2, pp. 661$665,2007$.
[107] Y. Feng, Y. Xia, G. Yu et al., "Cleavage of GSK-3 $\beta$ by calpain counteracts the inhibitory effect of Ser9 phosphorylation on GSK- $3 \beta$ activity induced by $\mathrm{H}_{2} \mathrm{O}_{2}$," Journal of Neurochemistry, vol. 126, no. 2, pp. 234-242, 2013.

[108] F. Chiara, A. Gambalunga, M. Sciacovelli et al., "Chemotherapeutic induction of mitochondrial oxidative stress activates GSK- $3 \alpha / \beta$ and Bax, leading to permeability transition pore opening and tumor cell death," Cell Death and Disease, vol. 3, no. 12, article e444, 2012.

[109] M.-H. Cho, D.-H. Kim, J.-E. Choi, and E.-J. Chang, "Increased phosphorylation of dynamin-related protein 1 and mitochondrial fission in okadaic acid-treated neurons," Brain Research, vol. 1454, pp. 100-110, 2012.

[110] L. Chen, L. Liu, and S. Huang, "Cadmium activates the mitogenactivated protein kinase (MAPK) pathway via induction of reactive oxygen species and inhibition of protein phosphatases 2A and 5," Free Radical Biology and Medicine, vol. 45, no. 7, pp. 1035-1044, 2008.

[111] M. A. Beydoun, M. T. Fanelli-Kuczmarski, M. H. Kitner-Triolo et al., "Dietary antioxidant intake and its association with cognitive function in an ethnically diverse sample of US adults," Psychosomatic Medicine, vol. 77, no. 1, pp. 68-82, 2015.

[112] S. Gillette-Guyonnet, M. Secher, and B. Vellas, "Nutrition and neurodegeneration: epidemiological evidence and challenges for future research," British Journal of Clinical Pharmacology, vol. 75, no. 3, pp. 738-755, 2013.

[113] M. A. Beydoun, H. A. Beydoun, A. A. Gamaldo, A. Teel, A. B. Zonderman, and Y. Wang, "Epidemiologic studies of modifiable factors associated with cognition and dementia: systematic review and meta-analysis," BMC Public Health, vol. 14, article 643, 2014.

[114] T. Hamaguchi, K. Ono, A. Murase, and M. Yamada, "Phenolic compounds prevent Alzheimer's pathology through different effects on the amyloid-beta aggregation pathway," The American Journal of Pathology, vol. 175, no. 6, pp. 2557-2565, 2009.

[115] J. Teixeira, T. Silva, P. B. Andrade, and F. Borges, "Alzheimer's disease and antioxidant therapy: how long how far?" Current Medicinal Chemistry, vol. 20, no. 24, pp. 2939-2952, 2013.

[116] C.-X. Peng, J. Hu, D. Liu et al., "Disease-modified glycogen synthase kinase- $3 \beta$ intervention by melatonin arrests the pathology and memory deficits in an Alzheimer's animal model," Neurobiology of Aging, vol. 34, no. 6, pp. 1555-1563, 2013.

[117] G. Benítez-King, L. Ortíz-López, G. Jiménez-Rubio, and G. Ramírez-Rodríguez, "Haloperidol causes cytoskeletal collapse in N1E-115 cells through tau hyperphosphorylation induced by oxidative stress: implications for neurodevelopment," European Journal of Pharmacology, vol. 644, no. 1-3, pp. 24-31, 2010.

[118] X.-C. Li, Z.-F. Wang, J.-X. Zhang, Q. Wang, and J.-Z. Wang, "Effect of melatonin on calyculin A-induced tau hyperphosphorylation," European Journal of Pharmacology, vol. 510, no. 1-2, pp. 25-30, 2005.

[119] J. B. Hoppe, R. L. Frozza, A. P. Horn et al., "Amyloid- $\beta$ neurotoxicity in organotypic culture is attenuated by melatonin: involvement of GSK- $3 \beta$, tau and neuroinflammation," Journal of Pineal Research, vol. 48, no. 3, pp. 230-238, 2010.

[120] L. Lin, Q.-X. Huang, S.-S. Yang, J. Chu, J.-Z. Wang, and Q. Tian, "Melatonin in Alzheimer's disease," International Journal of Molecular Sciences, vol. 14, no. 7, pp. 14575-14593, 2013.

[121] D. R. Galasko, E. Peskind, C. M. Clark et al., "Antioxidants for Alzheimer disease: a randomized clinical trial with cerebrospinal fluid biomarker measures," Archives of Neurology, vol. 69, no. 7, pp. 836-841, 2012. 
[122] M. Cente, P. Filipcik, S. Mandakova, N. Zilka, G. Krajciova, and M. Novak, "Expression of a truncated human tau protein induces aqueous-phase free radicals in a rat model of tauopathy: implications for targeted antioxidative therapy," Journal of Alzheimer's Disease, vol. 17, no. 4, pp. 913-920, 2009.

[123] I. Yoon, H. L. Kwang, and J. Cho, "Gossypin protects primary cultured rat cortical cells from oxidative stress- and $\beta$-amyloidinduced toxicity," Archives of Pharmacal Research, vol. 27, no. 4, pp. 454-459, 2004.

[124] N. Rajasekar, S. Dwivedi, S. K. Tota et al., "Neuroprotective effect of curcumin on okadaic acid induced memory impairment in mice," European Journal of Pharmacology, vol. 715, no. 1-3, pp. 381-394, 2013.

[125] O. B. Villaflores, Y.-J. Chen, C.-P. Chen, J.-M. Yeh, and T.-Y. Wu, "Effects of curcumin and demethoxycurcumin on amyloid- $\beta$ precursor and tau proteins through the internal ribosome entry sites: a potential therapeutic for Alzheimer's disease," Taiwanese Journal of Obstetrics \& Gynecology, vol. 51, no. 4, pp. 554-564, 2012.

[126] Q.-L. Ma, X. Zuo, F. Yang et al., "Curcumin suppresses soluble tau dinners and corrects molecular chaperone, synaptic, and behavioral deficits in aged human tau transgenic mice," Journal of Biological Chemistry, vol. 288, no. 6, pp. 4056-4065, 2013.

[127] M. Mutsuga, J. K. Chambers, K. Uchida et al., "Binding of curcumin to senile plaques and cerebral amyloid angiopathy in the aged brain of various animals and to neurofibrillary tangles in Alzheimer's brain," The Journal of Veterinary Medical Science, vol. 74, no. 1, pp. 51-57, 2012.

[128] H. J. Stuerenburg, S. Ganzer, and T. Müller-Thomsen, "Plasma betacarotene in Alzheimer's disease-association with cerebrospinal fluid beta-amyloid 1-40, (Abeta40), beta-amyloid 1-42 (Abeta42) and total Tau," Neuroendocrinology Letters, vol. 26, no. 6, pp. 696-698, 2005.

[129] Y. Chen, C. Wang, M. Hu et al., "Effects of ginkgolide a on okadaic acid-induced tau hyperphosphorylation and the PI3KAkt signaling pathway in N2a cells," Planta Medica, vol. 78, no. 12, pp. 1337-1341, 2012.

[130] F. V. Defeudis, "Bilobalide and neuroprotection," Pharmacological Research, vol. 46, no. 6, pp. 565-568, 2002.

[131] R. A. Frake, T. Ricketts, F. M. Menzies, and D. C. Rubinsztein, "Autophagy and neurodegeneration," The Journal of Clinical Investigation, vol. 125, no. 1, pp. 65-74, 2015.

[132] M. Damme, T. Suntio, P. Saftig, and E.-L. Eskelinen, "Autophagy in neuronal cells: general principles and physiological and pathological functions," Acta Neuropathologica, vol. 129, no. 3, pp. 337-362, 2015.

[133] A. Yamamoto and Z. Yue, "Autophagy and its normal and pathogenic states in the brain," Annual Review of Neuroscience, vol. 37, no. 1, pp. 55-78, 2014.

[134] R. A. Nixon, "The role of autophagy in neurodegenerative disease," Nature Medicine, vol. 19, no. 8, pp. 983-997, 2013.

[135] A. Efeyan, W. C. Comb, and D. M. Sabatini, "Nutrient-sensing mechanisms and pathways," Nature, vol. 517, no. 7534, pp. 302310, 2015.

[136] J. Bové, M. Martínez-Vicente, and M. Vila, "Fighting neurodegeneration with rapamycin: mechanistic insights," Nature Reviews Neuroscience, vol. 12, no. 8, pp. 437-452, 2011.

[137] S. F. Funderburk, B. K. Marcellino, and Z. Yue, "Cell 'self-eating' (autophagy) mechanism in Alzheimer's disease," Mount Sinai Journal of Medicine, vol. 77, no. 1, pp. 59-68, 2010.
[138] L. Li, X. Zhang, and W. Le, "Autophagy dysfunction in Alzheimer's disease," American Journal of Neurodegenerative Disease, vol. 7, no. 4, pp. 265-271, 2010.

[139] M. Ułamek-Kozioł, W. Furmaga-Jabłońska, S. Januszewski et al., "Neuronal autophagy: self-eating or self-cannibalism in Alzheimer's disease," Neurochemical Research, vol. 38, no. 9, pp. 1769-1773, 2013.

[140] J. L. Jewell, R. C. Russell, and K. L. Guan, "Amino acid signalling upstream of mTOR," Nature Reviews Molecular Cell Biology, vol. 14, no. 3, pp. 133-139, 2013.

[141] Z. Cai and L. J. Yan, "Rapamycin, autophagy, and Alzheimer's disease," Journal of Biochemical and Pharmacological Research, vol. 1, no. 2, pp. 84-90, 2013.

[142] E. A. Dunlop and A. R. Tee, "The kinase triad, AMPK, mTORC1 and ULK1, maintains energy and nutrient homoeostasis," Biochemical Society Transactions, vol. 41, no. 4, pp. 939-943, 2013.

[143] Y. Ishizuka, N. Kakiya, L. A. Witters et al., "AMP-activated protein kinase counteracts brain-derived neurotrophic factorinduced mammalian target of rapamycin complex 1 signaling in neurons," Journal of Neurochemistry, vol. 127, no. 1, pp. 66-77, 2013.

[144] C. H. Jung, M. Seo, N. M. Otto, and D.-H. Kim, "ULK1 inhibits the kinase activity of mTORC1 and cell proliferation," Autophagy, vol. 7, no. 10, pp. 1212-1221, 2011.

[145] M. C. Maiuri, S. A. Malik, E. Morselli et al., "Stimulation of autophagy by the p53 target gene Sestrin2," Cell Cycle, vol. 8, no. 10, pp. 1571-1576, 2009.

[146] E. Y. W. Chan, A. Longatti, N. C. McKnight, and S. A. Tooze, "Kinase-inactivated ULK proteins inhibit autophagy via their conserved C-terminal domains using an Atg13-independent mechanism," Molecular and Cellular Biology, vol. 29, no. 1, pp. 157-171, 2009.

[147] S. Sarkar, R. A. Floto, Z. Berger et al., "Lithium induces autophagy by inhibiting inositol monophosphatase," Journal of Cell Biology, vol. 170, no. 7, pp. 1101-1111, 2005.

[148] J. Zou, F. Yue, X. Jiang, W. Li, J. Yi, and L. Liu, "Mitochondrionassociated protein LRPPRC suppresses the initiation of basal levels of autophagy via enhancing Bcl-2 stability," Biochemical Journal, vol. 454, no. 3, pp. 447-457, 2013.

[149] M. Alirezaei, W. B. Kiosses, and H. S. Fox, "Decreased neuronal autophagy in HIV dementia: a mechanism of indirect neurotoxicity," Autophagy, vol. 4, no. 7, pp. 963-966, 2008.

[150] T. Shpilka, H. Weidberg, S. Pietrokovski, and Z. Elazar, "Atg8: an autophagy-related ubiquitin-like protein family," Genome Biology, vol. 12, no. 7, article 226, 2011.

[151] R. Kang, H. J. Zeh, M. T. Lotze, and D. Tang, "The Beclin 1 network regulates autophagy and apoptosis," Cell Death and Differentiation, vol. 18, no. 4, pp. 571-580, 2011.

[152] J. D. Lünemann, J. Schmidt, D. Schmid et al., " $\beta$-Amyloid is a substrate of autophagy in sporadic inclusion body myositis," Annals of Neurology, vol. 61, no. 5, pp. 476-483, 2007.

[153] P. A. Jaeger, F. Pickford, C.-H. Sun, K. M. Lucin, E. Masliah, and T. Wyss-Coray, "Regulation of amyloid precursor protein processing by the beclin 1 complex," PLoS ONE, vol. 5, no. 6, Article ID el1102, 2010.

[154] J. F. Ma, Y. Huang, S. D. Chen, and G. Halliday, "Immunohistochemical evidence for macroautophagy in neurones and endothelial cells in Alzheimer's disease," Neuropathology and Applied Neurobiology, vol. 36, no. 4, pp. 312-319, 2010.

[155] W. H. Yu, A. M. Cuervo, A. Kumar et al., "Macroautophagya novel Beta-amyloid peptide-generating pathway activated in 
Alzheimer's disease," The Journal of Cell Biology, vol. 171, no. 1, pp. 87-98, 2005.

[156] J. Perucho, M. J. Casarejos, A. Gomez, R. M. Solano, J. G. de Yébenes, and M. A. Mena, "Trehalose protects from aggravation of amyloid pathology induced by isoflurane anesthesia in APPswe mutant mice," Current Alzheimer Research, vol. 9, no. 3, pp. 334-343, 2012.

[157] A. Y. Lai and J. McLaurin, "Inhibition of amyloid-beta peptide aggregation rescues the autophagic deficits in the TgCRND8 mouse model of Alzheimer disease," Biochimica et Biophysica Acta-Molecular Basis of Disease, vol. 1822, no. 10, pp. 16291637, 2012.

[158] J. Wei, M. Fujita, M. Nakai et al., "Protective role of endogenous gangliosides for lysosomal pathology in a cellular model of synucleinopathies," The American Journal of Pathology, vol. 174, no. 5, pp. 1891-1909, 2009.

[159] R. A. Nixon, D.-S. Yang, and J.-H. Lee, "Neurodegenerative lysosomal disorders: a continuum from development to late age," Autophagy, vol. 4, no. 5, pp. 590-599, 2008.

[160] S. M. Cardoso, C. F. Pereira, P. I. Moreira, D. M. Arduino, A. R. Esteves, and C. R. Oliveira, "Mitochondrial control of autophagic lysosomal pathway in Alzheimer's disease," Experimental Neurology, vol. 223, no. 2, pp. 294-298, 2010.

[161] D. F. F. Silva, A. R. Esteves, D. M. Arduino, C. R. Oliveira, and S. M. Cardoso, "Amyloid- $\beta$-induced mitochondrial dysfunction impairs the autophagic lysosomal pathway in a tubulin dependent pathway," Journal of Alzheimer's Disease, vol. 26, no. 3, pp. 565-581, 2011.

[162] Y. Wang and E. Mandelkow, "Degradation of tau protein by autophagy and proteasomal pathways," Biochemical Society Transactions, vol. 40, no. 4, pp. 644-652, 2012.

[163] A. Caccamo, A. Magrì, D. X. Medina et al., "mTOR regulates tau phosphorylation and degradation: implications for Alzheimer's disease and other tauopathies," Aging Cell, vol. 12, no. 3, pp. 370380, 2013.

[164] Y. Liu, Y. Su, J. Wang et al., "Rapamycin decreases tau phosphorylation at Ser214 through regulation of cAMP-dependent kinase," Neurochemistry International, vol. 62, no. 4, pp. 458467, 2013.

[165] S. Ozcelik, G. Fraser, P. Castets et al., "Rapamycin attenuates the progression of tau pathology in P301S tau transgenic mice," PLoS ONE, vol. 8, no. 5, Article ID e62459, 2013.

[166] P. J. Dolan and G. V. W. Johnson, "A caspase cleaved form of tau is preferentially degraded through the autophagy pathway," The Journal of Biological Chemistry, vol. 285, no. 29, pp. 21978-21987, 2010.

[167] U. Krüger, Y. Wang, S. Kumar, and E.-M. Mandelkow, "Autophagic degradation of tau in primary neurons and its enhancement by trehalose," Neurobiology of Aging, vol. 33, no. 10, pp. 2291-2305, 2012.

[168] S.-I. Kim, W.-K. Lee, S.-S. Kang et al., "Suppression of autophagy and activation of glycogen synthase kinase 3beta facilitate the aggregate formation of tau," The Korean Journal of Physiology \& Pharmacology, vol. 15, no. 2, pp. 107-114, 2011.

[169] F. Lim, F. Hernández, J. J. Lucas, P. Gómez-Ramos, M. A. Morán, and J. Ávila, "FTDP-17 mutations in tau transgenic mice provoke lysosomal abnormalities and tau filaments in forebrain," Molecular and Cellular Neuroscience, vol. 18, no. 6, pp. 702-714, 2001.

[170] W.-L. Lin, J. Lewis, S.-H. Yen, M. Hutton, and D. W. Dickson, "Ultrastructural neuronal pathology in transgenic mice expressing mutant (P301L) human tau," Journal of Neurocytology, vol. 32, no. 9, pp. 1091-1105, 2003.

[171] A. Magnaudeix, C. M. Wilson, G. Page et al., "PP2A blockade inhibits autophagy and causes intraneuronal accumulation of ubiquitinated proteins," Neurobiology of Aging, vol. 34, no. 3, pp. 770-790, 2013.

[172] S. Y. Yoon, J. E. Choi, H.-S. Kweon et al., "Okadaic acid increases autophagosomes in rat neurons: implications for Alzheimer's disease," Journal of Neuroscience Research, vol. 86, no. 14, pp. 3230-3239, 2008.

[173] T. Hamano, T. F. Gendron, E. Causevic et al., "Autophagiclysosomal perturbation enhances tau aggregation in transfectants with induced wild-type tau expression," European Journal of Neuroscience, vol. 27, no. 5, pp. 1119-1130, 2008.

[174] Y. Wang, M. Martinez-Vicente, U. Krüger et al., "Tau fragmentation, aggregation and clearance: the dual role of lysosomal processing," Human Molecular Genetics, vol. 18, no. 21, pp. 4153$4170,2009$. 


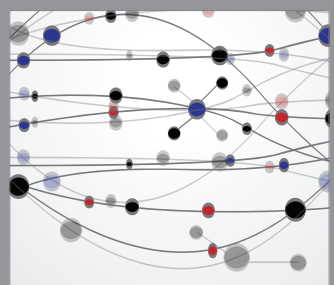

The Scientific World Journal
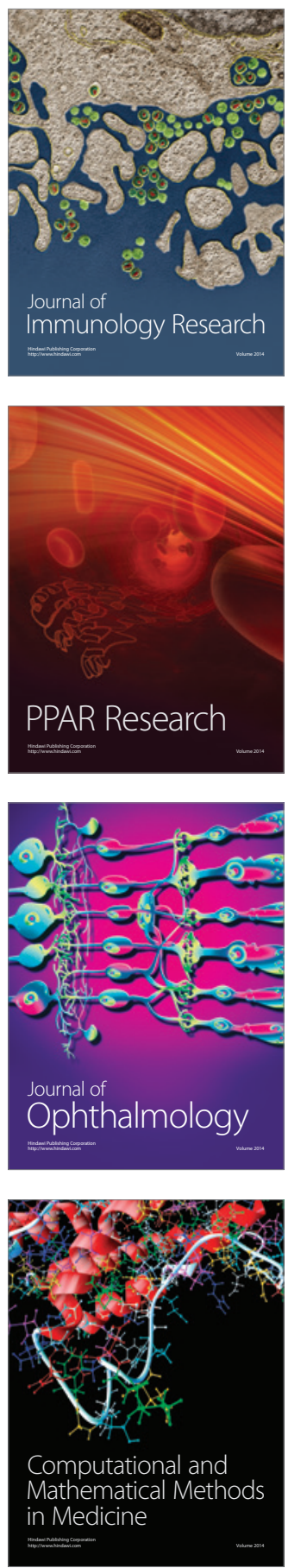

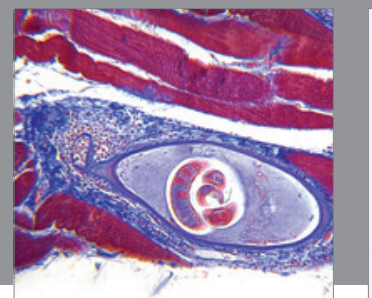

Gastroenterology

Research and Practice
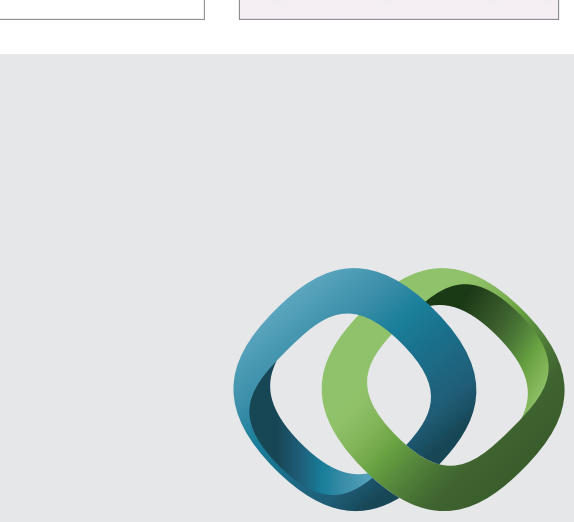

\section{Hindawi}

Submit your manuscripts at

http://www.hindawi.com
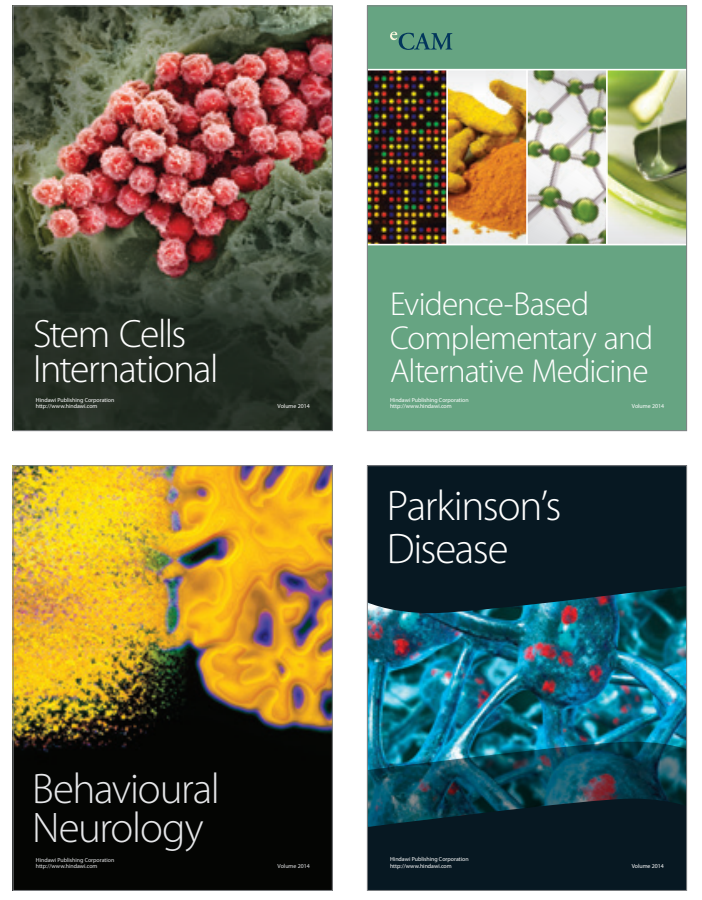
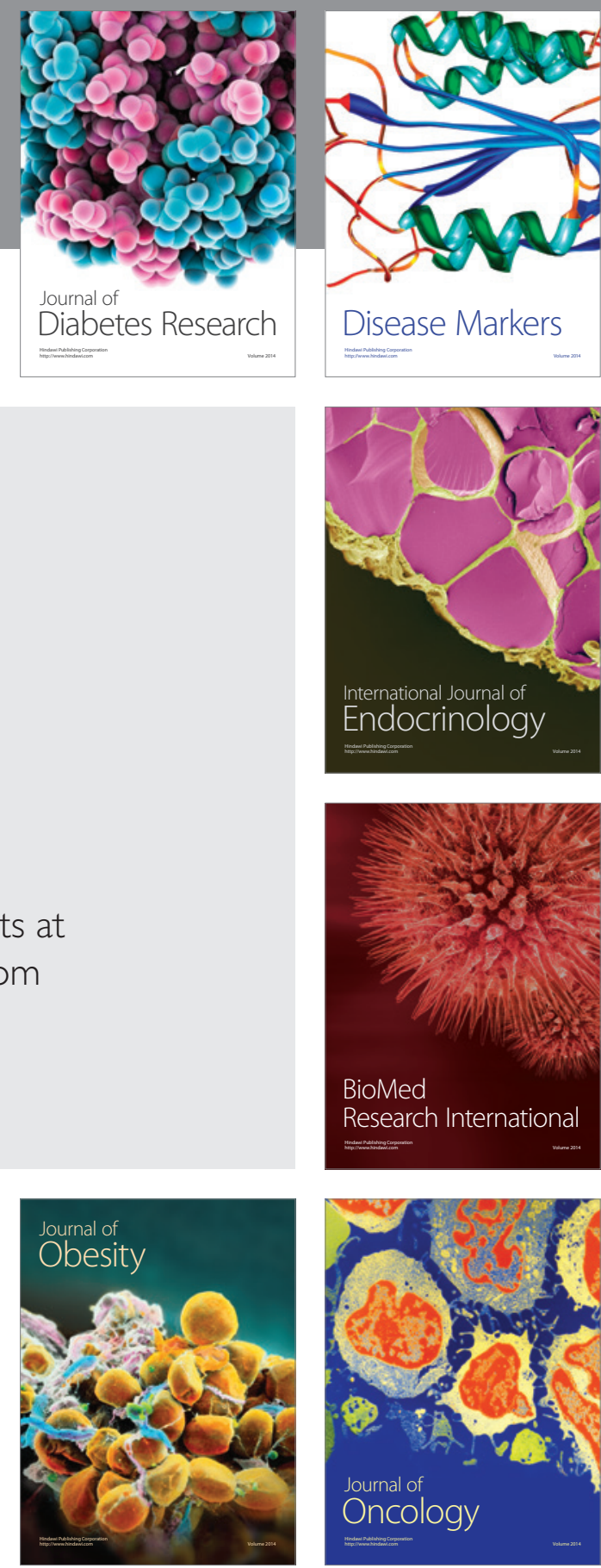

Disease Markers
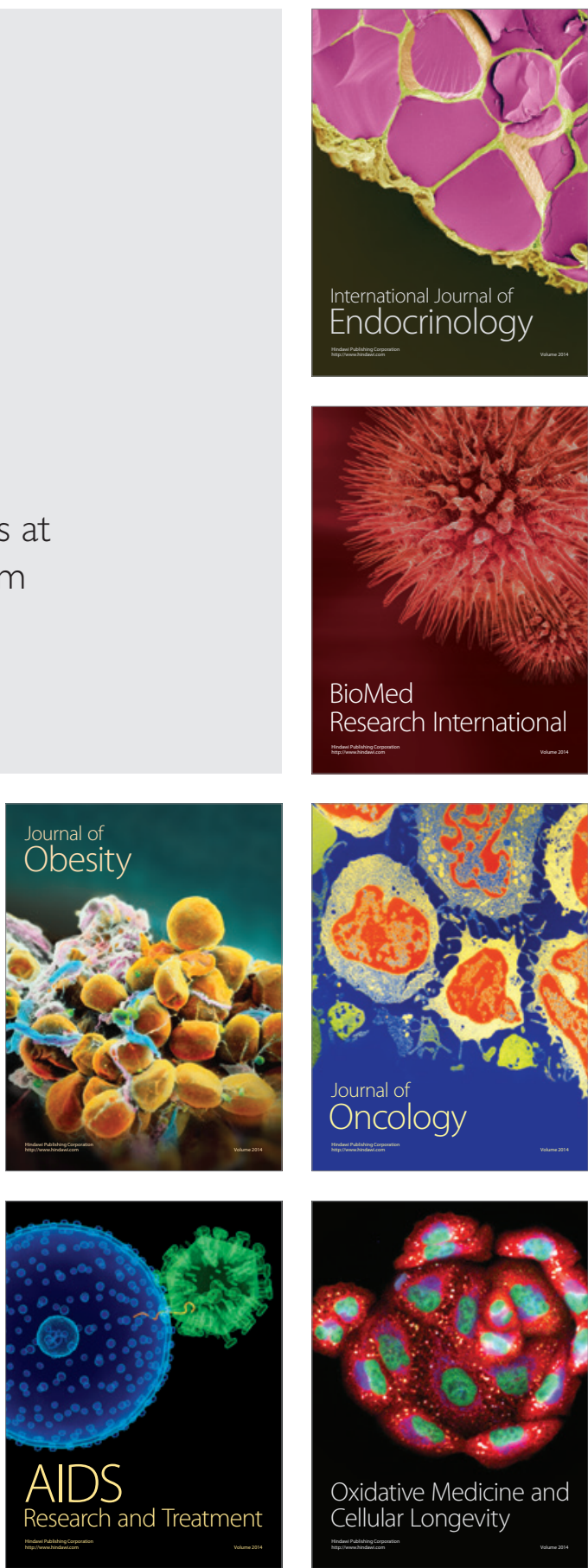